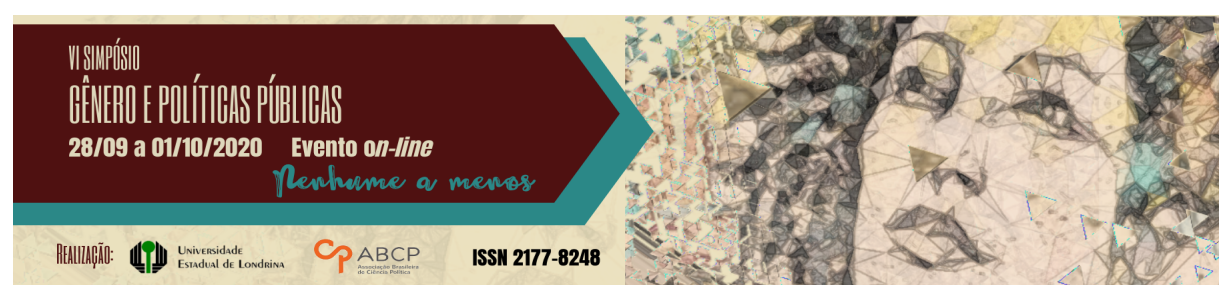

\title{
Mulheres, Autonomia e Participação Coletiva
}

\author{
Neuzeli Maria de Almeida Pinto ${ }^{1}$; Maria Mary Ferreira ${ }^{2}$
}

\section{Resumo}

Esse trabalho tem por objetivo analisar o processo de construção da autonomia de lideranças comunitárias e refletir sobre como articulam alternativas e possibilidades de desenvolvimento do trabalho produtivo, o qual se traduz em autonomia e posições que demarcam posturas de empoderamento. Participaram da pesquisa 14 mulheres trabalhadoras da Cooperativa COOPVILA, de fabricação de móveis de madeira reciclável, que atuam na comunidade da Vila Maranhão. No que se refere à metodologia, os aspectos pesquisados puderam ser obtidos através de diário de campo (DC), inventário sociodemográfico (ISD) e entrevistas semiestruturas (ESE). Os resultados finais apontaram para uma veemente interação entre as mulheres através do trabalho colaborativo e com autonomia, além do enfrentamento de preconceitos e formas de interdição que dificultaram o desenvolvimento do trabalho.

Palavras-chave: mulheres; gênero; trabalho; autonomia; participação.

\begin{abstract}
This work aims to analyze the process of building the autonomy of community leaders and reflect on how they articulate alternatives and possibilities for the development of productive work, which translates into autonomy and positions that demarcate positions of empowerment.

1 Docente do Departamento de Ciências Sociais e do Programa de Pós-Graduação em Desenvolvimento Socioespacial e Regional (PPDSR) da Universidade Estadual do Maranhão (UEMA); E-mail: neuzelialmeida@globo.com

2 Docente do Departamento de Biblioteconomia e do Programa de Pós-Graduação de Politicas Publicas (PPGPP) da Universidade Federal do Maranhão (UFMA); E-mail: mmulher13@hotmail.com
\end{abstract}

GT 03 - Feminismo, políticas públicas e novas estratégias de resistências: de marchas, movimentos e margaridas 
Participated in the research 14 women workers of the Cooperative COOPVILA, of manufacture of recyclable wooden furniture, who work in the community of Vila Maranhão. With regard to the methodology, the researched aspects could be obtained through a field diary (DC), sociodemographic inventory (ISD) and semi-structured interviews (ESE). The final results pointed to a vehement interaction between women through collaborative and autonomous work, in addition to facing prejudices and forms of interdiction that hindered the development of work.

Keywords: women; genre; job; autonomy; participation.

\section{Introdução}

Ao longo da história, o trabalho cooperado vem sendo uma das marcas do trabalho feminino, cuja invisibilidade tem contribuído para anular sua importância e dimensão social. O próprio sistema capitalista favorece a exploração dessa força de trabalho, desvalorizando-a e desqualificando-a. Para Silvia Federici (2019, p. 50), "para onde quer que olhemos, podemos observar que os trabalhos executados por mulheres são meras extensões da condição de dona de casa em todas as suas facetas". Portanto, é importante reafirmar que o trabalho cooperado possibilita o desenvolvimento individual e comunitário, e se contrapõe ao modelo capitalista a partir de estratégias de resistências que se constituem como formas de sobrevivência e autonomia das mulheres.

Conforme aponta Neuzeli Pinto (2012) e Isabelle Hillenkamp et al. (2016), as experiências denotam as formas de resistência das mulheres no trabalho cooperativo. O Maranhão é um dos estados brasileiros que se destaca pela diversidade de projetos solidários. Neste estudo, são observados os resultados de pesquisa que envolve 14 mulheres, lideranças comunitárias, as quais atuam na Cooperativa de Coleta e Recuperação de Resíduos da Vila Maranhão (COOPVILA), na Região Metropolitana de São Luís/MA. As mulheres trabalham no reaproveitamento de resíduos sólidos, sua principal fonte de renda. 
Há cerca de 15 anos, esse grupo de mulheres começou a recolher a madeira descartada pela Empresa VALE e indústrias instaladas na região do Itaqui. Nenhuma das envolvidas imaginou que a atividade chegaria tão longe. Inicialmente, trabalhando com a produção de carvão vegetal, a atividade se diversificou e a Cooperativa de Trabalho, Coleta e Recuperação de Resíduos da Vila Maranhão - COOPVILA passou a atuar também com marcenaria, com a fabricação de móveis charmosos, carregando a marca da sustentabilidade e da responsabilidade social e ambiental. Contudo, o exercício dessa atividade demanda esforço e grandes sacrifícios, expondo essas mulheres a situações de riscos à saúde, além de vulnerabilidades, desigualdades, preconceitos e obstáculos a serem superados.

O estudo da atuação das mulheres, sob a perspectiva sistêmica, requer metodologias capazes de captar a dinâmica das relações estabelecidas entre os diversos subsistemas, os quais compõem os contextos onde estão inseridas, dada a complexidade desse grupo. Dessa forma, foi adotado o método qualitativo, que possibilitou analisar o fenômeno e observar o desenvolvimento do trabalho realizado pelas cooperadas a partir da inserção das pesquisadoras no ambiente de estudo, denominado por Alessandra Cecconello e Silvia Koller (2003) de "inserção ecológica". Esse construto sugere que, ao entrar no contexto da investigação, a equipe de pesquisa integra-se a esse ambiente, tornando-se o mais próximo possível daqueles que o constituem (MENDES et al., 2008).

A participação nas oficinas e palestras propiciou $o$ conhecimento da realidade dessas mulheres e a sistematização das informações relativas aos contextos estudados. $\mathrm{O}$ conceito de inserção ecológica, segundo Cecconello e Koller (2003), refere-se à participação dos pesquisadores nos ambientes onde vivem ou transitam os pesquisados, com o objetivo de conhecer a realidade destes e sistematizar as informações relativas aos contextos estudados. 
Os instrumentos metodológicos adotados e que deram base à pesquisa são o diário de campo (DC), entrevista semiestruturada (ESE), que foram construídos para aplicação, e observação participante, caracterizada pelas intervenções com ações junto à comunidade, através de oficinas e palestras. Estas, por sua vez, foram adotadas como estratégias de interação e troca, refletindo sobre os dados colhidos de forma quantitativa e possibilitando maior compreensão do contexto em que essas mulheres atuam e do modo como constroem sua autonomia e empoderamento.

A inserção, portanto, teve como objetivo avaliar os processos de interação das pessoas com o contexto no qual se desenvolve o trabalho cooperativo com as mulheres na COOPVILA, apontado como uma alternativa de sobrevivência. Em função dessas premissas, os passos metodológicos desta pesquisa tiveram pretensões progressivas, implicando aproximações sucessivas que tornaram possíveis um acesso às informações, as quais realmente correspondam com a realidade da população investigada.

Por fim, é importante enfatizar, para melhor compreensão deste estudo, que sua estrutura está dividida em três momentos: uma introdução, na qual são expostos os propósitos dos estudos e o percurso metodológico; uma reflexão, que aborda os principais eixos teóricos, notadamente autonomia e empoderamento na perspectiva do trabalho comunitário; e os resultados e discussões da pesquisa empírica, que demonstra a permanência da participação ativa das mulheres nas atividades domésticas, sua dupla jornada de trabalho para conciliar essas atividades com o trabalho renumerado da COOPVILA e a forte presença nos movimentos comunitários.

\section{Autonomia das mulheres: o trabalho e sua atuação política e social}

O processo de formação social e política das mulheres na sociedade se constituiu a partir de determinações marcadas pelo gênero, compreendido como categoria histórica baseada num sistema 
hierárquico, presidindo as relações entre homens e mulheres, inseridos desigualmente nas estruturas de poder. O gênero é uma categoria central para entender e contextualizar como histórica e socialmente se reproduzem as relações sociais de gênero, também consideradas relações de poder. Ao longo da construção da humanidade, as mulheres foram alijadas dos espaços de decisão e silenciadas no mundo doméstico.

Nesse sentido, para compreender as relações desiguais de poder, o engessamento dos direitos das mulheres e a exclusão de sua participação nas tomadas de decisão, é preciso voltar a análise para o âmbito do público e do privado, tendo em vista que a organização das relações na vida privada estabelece barreiras à participação paritária de mulheres e homens na vida pública.

As mulheres, ao longo da história, foram sub-representadas, embora essa situação esteja sendo superada por muitos países da Europa e América Latina. Entretanto, no Brasil, as mulheres representam apenas $15 \%$ do Congresso Nacional, conforme estudos de Ferreira (2019). Esse fato reduz as possibilidades de que as questões que se definem como relevantes, a partir de experiências das mulheres na vida doméstica, fiquem invisibilizadas nas agendas e debates públicos (MIGUEL; BIROLI, 2014).

A dualidade entre as esferas pública e privada reforça no imaginário social o isolamento da mulher no âmbito privado. A desvalorização do trabalho doméstico, por exemplo, requer uma análise cuidadosa, uma vez que está relacionada à divisão sexual do trabalho e aos arranjos familiares convencionais. Por outro lado, é esse trabalho que permite que o homem seja liberado para atender às exigências profissionais que lhe permitem maior remuneração e construção de uma carreira e ocupação nos espaços de poder (MIGUEL; BIROLI, 2014).

Ao buscar explicações para a permanência das assimetrias entre homens e mulheres, Federici (2019) enfatiza que estas se devem à 
forma como a sociedade tem reagido às questões de gênero, uma vez que as atividades femininas são, em geral, consideradas irrelevantes, ou seja, o trabalho doméstico no bojo da acumulação capitalista, a desqualificação do fazer feminino ou a irrelevância, como são tratadas as atividades realizadas pelas mulheres, contribuem para naturalizar as assimetrias entre os homens e as mulheres. Tal fato, segundo a autora, se deve aos atributos de um sistema social de produção e pela reprodução que se alimenta de explorações e dominação, principalmente das mulheres. Ao se apropriar do trabalho doméstico, que é predominantemente feminino como fonte de acumulação do capital, a sociedade capitalista e patriarcal tira proveito da sua condição de trabalho não assalariado, criando desigualdades e hierarquias sexuais que vão sendo colocadas a serviço de um projeto de dominação, do qual as mulheres não farão parte.

A construção da autonomia das mulheres se insere como um dos pilares da luta feminista, que, nas suas várias expressões e correntes, tem sido uma referência para pensar as mulheres, seus direitos, seu reconhecimento, suas diferenças e sua busca por igualdade. Pensar a autonomia das mulheres é pensar formas de valorização e inserção das mesmas no mundo trabalho. Subentende-se, também, equacionar o trabalho produtivo e o reprodutivo de forma igualitária, responsabilizando os diversos membros da família para a divisão social das atividades domésticas, a fim de permitir que as mulheres possam participar das tomadas de decisão.

Autonomia também pode ser compreendida como a capacidade das mulheres de buscaram o seu próprio caminho, através de atitudes e da inserção em trabalhos coletivos remunerados, os quais têm contribuído para o seu empoderamento e tomada de suas próprias decisões. Esse processo se desenvolve a partir do conhecimento que adquirem sobre seus direitos, sobre a realidade e vulnerabilidades a que estão submetidas e sobre a necessidade de construir formas autônomas de sobrevivência e de enfrentamento. 
Pode-se, então, falar de autonomia das mulheres da COOPVILA a partir de três planos: autonomia simbólica-cultural, que expressa o reconhecimento das suas atividades exercidas; autonomia política, que envolve o princípio representativo; e autonomia econômica e material. O reconhecimento do trabalho das mulheres e a participação política através da cooperativa e associação conquistada pelas mulheres fazem parte de um processo em andamento, que se destaca pela articulação com instituições privadas, como a Empresa VALE e o SEBRAE Maranhão, para o desenvolvimento e qualificação do trabalho, além de participação política, empoderamento feminino e articulação em rede.

Desse modo, considera-se que o trabalho e a articulação dessas mulheres são definidos como uma rede, cujas práticas políticas se entrelaçam nos três níveis articulatórios do movimento em rede, assim como nos três componentes da construção política: multiforme, pluritemático e interorganizacional, conforme aponta Ilse SchererWarren (2006):

As redes, por serem multiformes, aproximam atores sociais diversificados - dos níveis locais aos mais globais, de diferentes tipos de organizações, e possibilitam o diálogo da diversidade de interesses e valores. Ainda que esse diálogo não seja isento de conflitos, o encontro e o confronto das reivindicações e lutas referentes a diversos aspectos da cidadania vêm permitindo aos movimentos sociais passarem da defesa de um sujeito identitário único, à defesa de um sujeito plural (SCHERERWARREN, 2006, p. 115-6).

Nesse processo de luta e reconhecimento, a autonomia é um quesito fundamental, pois compreende a capacidade que um grupo ou pessoa tem de decidir sobre questões que são de seu interesse. Tal conceito vem sendo empregado em vários âmbitos pelo movimento feminista, movimento de mulheres, movimento de mulheres rurais e no âmbito das políticas públicas, que visam maior equidade de gênero (GOHN, 2004). 
A luta pela igualdade de gênero, seja nos contextos urbanos ou rurais, salienta-se nas interações que as lideranças comunitárias mantêm e resultam nas relações da rede de apoio, constituindo sempre desafios que se concretizam no cotidiano das famílias da comunidade. Processos como o trabalho e as relações sociais exercidas na comunidade fornecem às mulheres condições para manejar a força de trabalho para fora da esfera privada, proporcionando modificações nas relações sociais, culturais, políticas e financeiras.

Portanto, essas mulheres passam a exercer o seu poder na família, no trabalho e na comunidade, fomentando processos de empoderamento. Com efeito, “o que precisa ficar patente é que o poder pode ser democraticamente partilhado, gerando liberdade e igualdade, como também pode ser exercido discricionariamente, criando desigualdades" (SAFFIOTI, 2009, p. 18).

\section{Mulheres da COOPVILA: experiências de autonomia}

A comunidade estudada, Vila Maranhão, localiza-se ao oeste da ilha de São Luís, no estado do Maranhão, distante cerca de 22 quilômetros do centro da cidade, a 14 quilômetros do perímetro urbano. Essa comunidade passou a sofrer forte influência dos grandes projetos industriais a partir do final da década de 1970, primeiramente com a Empresa de Alumínios do Maranhão (ALUMAR, do grupo da transnacional ALCOA), no extremo oeste da ilha, e depois com a Companhia Vale do Rio Doce (CVRD), maior exportadora mundial de minério de ferro, através do sistema da Estrada de Ferro Carajás Porto do Itaqui.

As características agrárias da Vila Maranhão são refletidas nas atividades de subsistência agrícola e pesqueira nos manguezais relativamente bem conservados do entorno, os quais favorecem a alimentação da população local através da coleta de caranguejos, sururus e da pesca artesanal. Observa-se que os manguezais que alimentam a população vêm sendo devastados pela expansão dos 
portos de exportação de minérios, passando a ter sua sustentabilidade ameaçada.

A região metropolitana de São Luís é populosa, com um milhão e cinquenta e três mil habitantes. A cidade tem crescido de maneira desordenada, muitas vezes interligada por pontes e estradas de difícil acesso. Essa região é composta por três grandes municípios, além de São Luís, que são: São José de Ribamar, Raposa e Paço de Lumiar. Muitas escolas enfrentam dificuldades com quadro de professores e evasão dos alunos antes da conclusão do Ensino Médio. A falta de oportunidades marca a vida dos jovens dessa região, assim como de toda a ilha.

No que se refere às mulheres, sua inserção no mercado formal de trabalho e no ensino, além do próprio papel que ela desempenha no âmbito doméstico, são comprometidos pela situação de vulnerabilidade em que se encontram. O motivo são as discriminações e violências que sofrem nos contextos em que estão inseridas.

As mulheres da comunidade de Vila Maranhão têm uma participação ativa no processo político e econômico do local. O trabalho remunerado dessas mulheres proporciona sua emancipação econômica e tem sido de grande estímulo para o surgimento de esforços suplementares que atendem às suas necessidades no seio da família e a de outros membros, parentes e vizinhos. A condição social e o modo de sobrevivência ativam uma rede de apoio e contribuem, em grande parte, para construir a autonomia dessas mulheres.

A partir do exposto, interessa compreender a relação entre o modo de sobrevivência e a rede de apoio desenvolvida nessa comunidade, fato que implica entender mecanismos relacionais de caráter sociocultural, ou seja, identificar como as mulheres se organizam nos contextos em que elas atuam na comunidade Vila Maranhão. O objetivo é estruturar as relações de trabalho, as relações familiares e as relações de gênero nas associações. 
Participaram desta pesquisa 14 mulheres trabalhadoras da comunidade Vila Maranhão, na Região Metropolitana de São Luís/MA, que trabalham na Cooperativa de Trabalho Coleta e Recuperação de Resíduos da Vila Maranhão (COOPVILA). Essa cooperativa passou a atuar também com marcenaria, com a fabricação de móveis charmosos, carregando consigo a marca da sustentabilidade e da responsabilidade social e ambiental. Conforme mencionado, essas mulheres desenvolvem seu trabalho no reaproveitamento de resíduos sólidos, sua principal fonte de renda. É uma atividade que não tem nenhum vínculo empregatício com a Vale.

É importante destacar que o trabalho realizado por essas mulheres as expõe a grandes sacrifícios e situações de riscos à saúde, além de vulnerabilidades e precariedades, que são considerados como obstáculos a serem superados por elas. Entretanto, observou-se no decorrer da pesquisa que essa situação de risco e do trabalho precário são perceptíveis para as trabalhadoras. Mesmo assim, elas naturalizam essa situação, considerando que são estágios e etapas que vão sendo superadas no processo, na luta. Elas se consideram vitoriosas e são extremamente motivadas, mas não se dão conta do processo de exploração da Vale sobre o trabalho que desenvolvem, veem como uma parceria. Contudo, é importante ressaltar que a Vale utiliza esse programa de sustentabilidade e inserção da comunidade do entorno para sua promoção social e ambiental.

A COOPVILA consolidou o trabalho dos cooperados, que também recebe o apoio do Sebrae no Maranhão. Hoje, a cooperativa tem sede oficial, onde funciona a administração dos negócios, e está instalada em uma área externa à produção do carvão de madeira, que é reaproveitado em um forno projetado para causar o menor dano ambiental possível. É uma tecnologia que condensa a fumaça produzida durante o processo, resultando no pirolenhoso, um líquido que serve para a produção de adubo e também entra como componente do asfalto - mais um produto que passará a ser comercializado pelo grupo. 


\section{A relação de vulnerabilidade no trabalho e os desafios apontados pelas mulheres}

As situações que colocam a mulher em situação de vulnerabilidade costumam resultar da relação hierárquica estabelecida entre os sexos, comentada acima, e naturalizada ao longo do percurso histórico, em razão da divisão dos papéis que são instituídos socialmente aos diferentes gêneros.

Dentre as funções destinadas às mulheres está o cuidado com a casa e com os filhos, que, geralmente, é associado ao estigma da ocupação desqualificada das mulheres no mercado de trabalho. Por isso, diversas mulheres conciliam o trabalho informal com os afazeres domésticos. Ao assumirem as atividades domésticas, as mulheres lidam com dificuldades financeiras, sociais e culturais em seu cotidiano, as quais influenciam a vulnerabilidade familiar diariamente (PINTO et al., 2011).

Por essa razão, enquanto aos homens costumam ser atribuídas qualidades referentes ao espaço público, à agressividade, as mulheres são representantes do "sexo frágil", às quais convém traços de afeição e sensibilidade. Nessa contraposição, desde a infância delineia-se uma sociedade que trata a mulher como passiva e, portanto, vulnerável.

Ao colocar em análise as relações de gênero, um dos reflexos está relacionado à inserção da mulher no mercado de trabalho, o que apesar de representar uma grande conquista - acarreta uma série de responsabilidades. Ao passo que a mulher expande seu leque de oportunidades para a remuneração, ela ainda sustenta um repertório tradicional de execuções ligadas ao cuidado com as tarefas domésticas, o zelo pelo lar e pelos filhos. Mesmo que as funções da família sejam executadas por outras pessoas, a mulher acaba sendo detentora da maior parte dos trabalhos domésticos. 
Betânia Ávila e Verônica Ferreira (2014) reforçam essa discussão e colocam a divisão sexual do trabalho como uma prática que ocorre no interior de cada uma de suas esferas. No campo produtivo, há uma concepção sobre o que é o trabalho de homens e o que é o trabalho de mulheres, resultando numa divisão de tarefas correspondentes. Essa divisão incide também sobre o valor do trabalho dos homens e das mulheres, expresso na desigualdade de salários. Além disso, no trabalho produtivo há uma captura das habilidades desenvolvidas no trabalho doméstico, a qual, além de ser apropriada como forma de exploração do trabalho das mulheres, pode funcionar também como meio de reafirmação da naturalização dessas habilidades, tornando-se algo inerente à concepção de um ser feminino e como justificativa da desigualdade salarial.

Esses danos se manifestam nas oportunidades de inserção da mulher no mercado de trabalho, as quais, geralmente, são inferiores à condição masculina, posto que as ofertas salariais são reduzidas e se destinam a trabalhos com pouca qualificação e reconhecimento.

Quanto às mulheres de classes populares, há ainda maior fragilidade ao adentrar nessas questões. Além de serem responsabilizadas pelo trabalho remunerado, elas também devem executar as tarefas domésticas e cuidar da educação de filhos e do bem-estar da família. Assim, enquanto os maridos trabalham em outros setores, as mulheres trabalham em atividades consideradas não rentáveis. Grande parte desses trabalhos é realizado nas próprias casas, nos quintais das famílias, sendo, às vezes, a única atividade remunerada da casa. Ainda assim, a função de provedor e "chefe" da família é delegada aos homens.

Nessa perspectiva, é perceptível a autonomia de mulheres que exercem o trabalho remunerado, haja vista que - segundo elas mesmas - isso transmite maior poder de decisão. Segundo essas mulheres, as atividades de trabalho remunerado contribuem diretamente para esse sentimento de autonomia, o qual proporciona maior conforto diante de situações de dificuldades. Assim, a remuneração reduziria os 
processos de silenciamento e de violência simbólica vivenciados por essas mulheres.

Cabe refletir para fins deste trabalho: quais as principais situações-problema vivenciadas pelas mulheres, mães e integrantes de uma cooperativa de reciclagem de madeira na Vila Maranhão? Partese do pressuposto de que as mulheres em condição de vulnerabilidade lidam cotidianamente com dificuldades financeiras, discriminação social e podem negligenciar sua autonomia em prol da constituição familiar. Também é possível que as condições de vulnerabilidade nas quais a mulher e sua família se encontram possam influenciar negativamente as suas relações familiares e sociais, resultando num ambiente familiar e comunitário instável.

A relevância deste estudo reside no fato de que, atualmente, a atividade de reciclagem desenvolvida pela COOPVILA é um importante meio de complementação de renda dessas mulheres. Percebe-se, então, a necessidade de se compreender melhor a atuação da mulher na cooperativa, no desenvolvimento do trabalho e no modo como se dá a construção da autonomia, empoderamento e identidade dessas mulheres. Ao fomentar a compreensão das mulheres, mães e cooperadas, enfoca-se o estudo do gênero e o empoderamento das mulheres no contexto do trabalho. Ademais, é importante compreender esse sentimento que norteia o protagonismo dessas mulheres em tantos espaços, incluindo a visão de identidade relacionada ao processo de efetivação das atividades desenvolvidas por elas, o que se chama de autonomia e empoderamento, conforme apresentado no item anterior.

O efetivo autonomia dependem de condições para que as mulheres assumam o seu papel de agente social, tanto no que se refere à eliminação das iniquidades ou injustiças, que prejudicam o seu bemestar, quanto ao seu reconhecimento, que também influencia a independência econômica e emancipação social (SEN, 2000). Isso implica reconhecer suas liberdades de escolhas, de modo que possam trabalhar fora de casa, "ter direitos de propriedade, ser alfabetizada e 
participar como pessoas instruídas nas decisões dentro e fora da família" (SEN, 2000, p. 220-222).

Neste trabalho, pode-se caracterizar e relacionar o contexto vivenciado por essas mulheres a três aspectos inovadores nas relações de gênero, os quais as mulheres vivenciam na atualidade: relações desiguais construídas socialmente, autonomia e estratégias transversalizadas que promovem o senso de responsabilidade das mulheres que sofrem com a discriminação.

As participantes que compõem o presente estudo têm um histórico de vulnerabilidade como catadoras de madeiras descartadas pela Empresa Vale, exercem suas atividades no meio de tratores e vivenciam riscos com materiais que são manipulados para a retirada de pregos e farpas, e com animais peçonhentos, como escorpiões, cobras, aranhas, etc. A maior parte dos resíduos é coletada na área da Vale, sendo o principal a madeira (pallets), seguida pelos resíduos de obras da construção civil.

No decorrer do desenvolvimento das atividades do projeto, as beneficiárias começaram a agregar valores aos resíduos coletados, iniciando a produção de carvão, a recuperação de telhas de amianto, a padronização de madeiras próprias para lenha. Essa atividade possibilitou um aumento de renda, desenvolvimento de estratégias de inclusão, maior autonomia e empoderamento das trabalhadoras.

Federici (2019) registra o lar como um "lugar de resistência", onde as contradições inerentes ao "trabalho alienado" são mais explosivas para a prática revolucionária. A autora também descreve que é pelas atividades do dia a dia, através das quais são produzidas a existência, que se pode desenvolver a capacidade de cooperação e não só resistir à desumanização, mas aprender a reconstruir o mundo como espaço de educação, criatividade e cuidado.

Com esse tipo de trabalho, as mulheres conseguem articular outros membros da família, como os filhos, irmãos e maridos. Estes se integram à execução das atividades com os resíduos de madeiras e 
fabricação de móveis. Além disso, outras organizações envolvidas no Projeto da COOPVILA dão suporte para a realização dessas ações, como o fornecimento de auxilio técnico e transporte da produção. Conforme é demonstrado nos resultados, as participantes relatam que o desenvolvimento do projeto funciona como fator fundamental para a manutenção de uma visão positiva da realidade e motivação para aspiração de novas conquistas e melhoria das condições de vida da comunidade.

A atuação das mulheres em vários contextos da comunidade garante a elas maior autonomia e liderança comunitária. Segundo Sônia, uma das lideranças da comunidade, as mulheres dentro desse espaço atuam em diversos locais e assumem papéis de grande importância:

Oh aqui os papéis que mais se destaca são das mulheres. No caso a presidenta da associação é mulher né, a questão da igreja é mais mulher que fica nessa parte, na escola nossas mulheres têm bastante participação (Sônia, 2018 - COOPVILA).

A participação das mulheres nesses espaços possibilita a construção de uma extensa rede de relações, a qual contribui para que obtenham autonomia e empoderamento político, "incentivando-as" a participarem das decisões da comunidade. A articulação nas redes de relações constitui-se num mecanismo importante para o contexto das famílias, pois é com essa rede que as mulheres contam para realizar atividades fora do âmbito doméstico.

Segundo Carlos Sluzki (2003), a função das redes de apoio social está atrelada à companhia social, apoio emocional, guia cognitivo, conselho, regulação social, ajuda material e de serviços e acesso a novos contatos. Dentre estas, a função de apoio é considerada de grande relevância para o trabalho com as famílias e a comunidade. Logo, rede de apoio social faz referência às funções que presta e ao efeito de bem-estar sentido pelas pessoas. Rede de apoio social também pode ser definida como "provisões instrumentais ou 
expressivas, reais ou percebidas, dadas pela comunidade, redes sociais e amigos íntimos" (LÓPEZ-CABANAS, 1997, p. 185).

As relações de articulação mantidas pelas mulheres possibilitam que, muitas vezes, ao exercerem atividades remuneradas fora do âmbito da casa, acionem essa rede para realização das atividades domésticas, ou, até mesmo, para ajudar no cuidado com os filhos. Esse aspecto é verificado quando as mulheres da referida comunidade foram questionadas sobre abrir mão de alguma atividade remunerada para o cuidado com a casa ou com os filhos. As mesmas sempre apontam que contam com o apoio familiar para não abrirem mão das atividades.

Não. Teve uma época que quase que teve um serviço pra que eu fosse pra outro município que era Bacurituba e Cajapió que são bem distante, então tinha que passar a semana toda. Então nessa época assim logo no princípio foi muito difícil porque os meninos estão ainda muito pequenos, ainda bem que tem uma família que sempre tá apoiando, mas ainda bem que com o apoio da família eu acabei indo. Passava a semana e sextafeira eu já tava de volta aqui com os meninos (Francisca/COOPVILA - 2018).

Não. Quando eu tenho oportunidade de trabalho eu vou buscar. Nunca me impediu (Rose/COOPVILA2018).

É a partir dessa rede que as mulheres da comunidade conseguem sua autonomia econômica. Muitas dessas mulheres acionam as famílias quando necessitam de ajuda com os filhos para exercerem trabalhos remunerados, garantindo a sua autonomia econômica. É nessa perspectiva que Federici (2019) discute esse lugar com a retomada dos comuns, que, segundo ela, constitui a forma mais antiga de organização do trabalho reprodutivo, pois indica para um horizonte de coletividade, resistência e solidariedade, responsáveis por romper com a estrutura capitalista de exploração nas sociedades. 
São histórias de mulheres que produzem comuns, como, por exemplo, as cozinhas populares, os artesanatos coletivos, as creches comunitárias. São formas importantes de sobrevivência utilizadas pelas mulheres. São experiências de organização e de reapropriação da capacidade e iniciativa das mesmas, um jeito de dizer "eu sou capaz de fazer algo para mudar a minha vida". É preciso juntar-se com outras pessoas para organizar uma vida econômica, criar uma rede de solidariedade num mundo que tende a separar, a individualizar. Isso não significa abandonar completamente a luta pelo salário, a luta pela moradia, mas fortalecer a luta de uma com as outras.

A cooperativa (COOPVILA) traz essa realidade descrita pela autora, fundada por Dona Aldeci, uma das lideranças da comunidade. É de grande importância para as mulheres, pois é através da articulação da sua liderança que a COOPVILA mantém os projetos que entram na comunidade. Um deles é a construção do galpão que hoje é utilizado pelas mulheres para realização do trabalho com a madeira.

A participação feminina dentro da comunidade é bastante significativa, tanto no processo de produção econômica das famílias quanto na participação de decisões políticas.

O centro de produção, onde funciona a marcenaria, o forno que fabricamos o carvão e até o terreno onde trabalhamos foi com o nosso esforço para conseguir com as empresas que apoia a gente (Aldeci/ COOPVILA).

As mulheres da COOPVILA realizam a confecção dos móveis. Contudo, para a maior parte das trabalhadoras, o trabalho com a reciclagem da madeira constitui o principal rendimento da família.

As mulheres da comunidade também encontram dificuldade na realização do trabalho quando "necessitam" da mão de obra masculina para algumas tarefas. Mesmo quando os homens não podem efetuar determinada função, elas costumam se juntar e fazer a tarefa. 
As maiores dificuldades é com os homem. Quando eles não querem levar as coisas com a gente a gente vai e faz sozinha (Lourdes, 2018).

Essa união mostra que, apesar das dificuldades encontradas pelas mulheres na realização do trabalho, a colaboração entre elas favorece a realização das atividades.

As mulheres da COOPVILA possuem forte e ativa participação política na cooperativa. Esse envolvimento no processo de organização e busca por melhores condições para a comunidade contribui, de certa forma, para que as mulheres se reconheçam como sujeitos políticos e com grande autonomia, conferindo-lhes empoderamento para reforçar a articulação e liderança dentro do grupo.

\section{Considerações Finais}

Pode-se dizer que o trabalho desenvolvido pelas mulheres da COOPVILA contribui para a autonomia das trabalhadoras no que tange à econômica e maior participação política. Nesse sentido, percebe-se a relação de poder que perpassa as relações sociais, econômicas e pessoais.

Identificou-se a constituição das relações de gênero organizadas para fins de estruturação das relações familiares, execução das atividades e função do papel feminino no sistema comunitário como um todo, além do modo como se estrutura a autonomia nessas relações. Observou-se que esses fatores integram entre si relações e constituem desafios, os quais se concretizam no cotidiano das mulheres, nas relações no interior da família, no trabalho e na comunidade em que participam.

A possível procura por outras saídas para os momentos difíceis da vida cotidiana faz com que as mulheres sejam levadas a se deslocar do âmbito doméstico para o público, organizando-se e, inclusive, participando de ações coletivas. Este estudo demonstra que uma rede de apoio social permite às mulheres a circulação em vários contextos, 
bem como a interação entre pessoas de outros microssistemas de modo adaptado e com equilíbrio nas relações de poder. Essa interação contribui para o sucesso na execução das atividades.

Ademais, as experiências das trabalhadoras da COOPVILA podem implicar transformações no âmbito doméstico e criar novas condições para a presença feminina nos espaços públicos, estabelecendo, assim, uma nova reintegração entre público e privado. São mudanças que também favorecem os processos de transformações macrossociais.

Apesar da comunidade ter se beneficiado de intervenções institucionais, inclusive com a difusão de novas tecnologias, verifica-se que as famílias ainda permanecem em um contexto de empobrecimento econômico local. Entretanto, mesmo com o aspecto de desvalorização do trabalho feminino, constatou-se durante a pesquisa que o seu posicionamento na estrutura familiar é considerado dinâmico e abrange um aglomerado de sistemas que mantêm relações interdependentes entre si.

No que tange à autonomia e empoderamento das mulheres, foi possível perceber que existe um processo específico de mudança em torno da constituição de formas de autonomia, as quais incidem nas relações mais impositivas e participativas das mulheres na cooperativa. Essas formas de autonomia envolvem decisões na comunidade, que também estão estritamente ligadas à independência financeira das mulheres e ao maior poder no âmbito doméstico.

\section{Referências}

ÁVILA, Maria Betânia; FERREIRA, Verônica. “Trabalho produtivo e reprodutivo no cotidiano das mulheres brasileiras". In: ÁVILA, Maria Betânia; FERREIRA, Verônica. (Org.). Trabalho remunerado e trabalho doméstico no cotidiano das mulheres. Recife: SOS CORPO Instituto Feminista pela Democracia; Instituto Patrícia Galvão, 2014. p. 14-49. 
CECCONELLO, Alessandra Marques; KOLLER Silvia Helena. "Inserção ecológica na comunidade: uma proposta metodológica para o estudo de famílias em situação de risco". Psicologia Reflexão e Crítica, Porto Alegre, v. 16, n. 3, 2003.

COSTA, Ana Alice Alcantara. Gênero, poder e empoderamento das mulheres. Salvador: Núcleo de Estudos Interdisciplinares sobre a Mulher (NEIM/UFBA), 2000.

COSTA, Ana Alice Alcantara; SARDENBERG, Cecília Maria Bacellar. "A transversalização de Gênero e Raça no Plano Nacional de Qualificação: análise crítica e diretrizes”. Ser Social, Brasília, v. 10, p. 101-138, 2008.

EYBEN, Rosalind. "Dando suporte às trilhas do empoderamento de mulheres: Um breve guia para agências internacionais de desenvolvimento". Revista Feminismos, v. 1, n. 2. maio/ago. 2013.

FEDERICI, Silvia. O Ponto zero da revolução: trabalho doméstico, reprodução e luta feminista. São Paulo: Elefante, 2019.

FERREIRA, Maria Mary et al. (Org.). Mulheres e Protagonismo Político no Maranhão: elementos para a superar a Sub-representação feminina. São Luís: EDUFMA; NIEPEM, 2019.

GOHN, Maria da Glória. "Empoderamento e participação da comunidade em políticas sociais". Saúde e Sociedade, v. 13, n. 2, p. 2031, ago. 2004.

HILLENKAMP, Isabelle; GUERÍN, Isabelle; VERSCHUUR, Christine. "A economia solidária e as teorias feministas: possíveis caminhos para uma convergência necessária". Sempreviva Organização Feminista, 07 out. 2016. Disponível em: https:/ / www.sof.org.br/aeconomia-solidariaeasteoriasfeministaspossiveis-caminhos-para-uma-convergencia-necessaria/. Acesso em: 08 jan. 2020.

LÓPEZ-CABANAS, Miguel. “Apoyo social, redes sociales e grupos de autoayuda". In: LÓPEZ-CABANAS, Miguel; CHACÓN, Fernando. Intervención Psicosocial y servicios sociales. Un enfoque participativo. Madrid: Síntesis Psicológica, 1997.

MENDES, Leila Said Assef et al. (2008). “Inserção Ecológica no Contexto de uma Comunidade Ribeirinha Amazônica". Revista 
Interamericana de Psicología/Interamerican Journal of Psychology, v. 42, n. 1, p. 1-10, 2008.

MIGUEL, Luís Felipe; BIROLI, Flávia. Feminismo e política: uma introdução. São Paulo: Boitempo, 2014.

PINTO, Neuzeli M. de Almeida. "O Papel das mulheres na Elaboração de Estratégias de Sobrevivência". In: FERREIRA, Maria Mary (Org.). Conhecimento feminista e relações de gênero no Norte e Nordeste brasileiro. São Luís: Redor; NEPEM, 2012.

PINTO, Rosa Maria Ferreiro et al. Condição feminina de mulheres chefes de família em situação de vulnerabilidade social. Serv. Soc. Soc., São Paulo, n. 105, p. 167-179, 2011.

SAFFIOTI, Heleieth Iara Bongiovani (2009). Ontogênese e filogênese do gênero: ordem patriarcal de gênero e a violência masculina contra mulheres. Brasília: FLACSO Brasil, 2009. (Série Estudos/Ciências Sociais).

SARDENBERG, Cecília Maria Bacellar. Conceituando 'Empoderamento' na perspectiva feminista. Repositório Institucional da Universidade Federal da Bahia, Salvador, 2006.

SCHERER-WARREN, Ilse. Das mobilizações às redes de movimentos sociais. Sociedade e Estado, Brasília, v. 21, n. 1, p. 109-130, jan. /abr. 2006.

SEN, Amartya. Desenvolvimento como liberdade. São Paulo: Companhia das Letras, 2000.

SLUZKI, Carlos E. A rede social na prática sistêmica. 2. ed. São Paulo, SP: Casa do Psicólogo, 2003. 